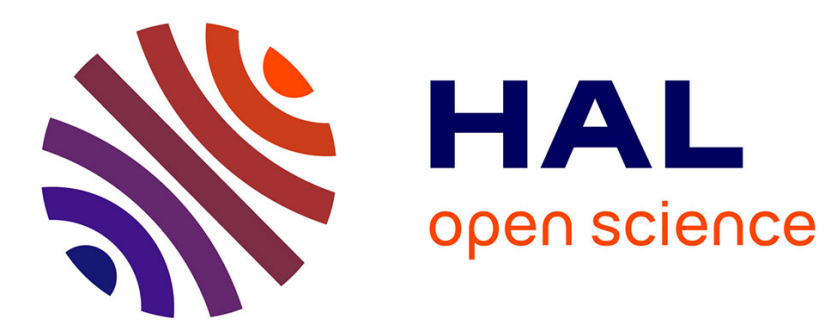

\title{
Causality and conservation of energy : their implications for prediction of receiver performance D. Leikin
}

\section{To cite this version:}

D. Leikin. Causality and conservation of energy: their implications for prediction of receiver performance. Journal de Physique IV Proceedings, 1994, 04 (C5), pp.C5-1323-C5-1326. 10.1051/jp4:19945294 . jpa-00253007

\section{HAL Id: jpa-00253007 https://hal.science/jpa-00253007}

Submitted on 1 Jan 1994

HAL is a multi-disciplinary open access archive for the deposit and dissemination of scientific research documents, whether they are published or not. The documents may come from teaching and research institutions in France or abroad, or from public or private research centers.
L'archive ouverte pluridisciplinaire HAL, est destinée au dépôt et à la diffusion de documents scientifiques de niveau recherche, publiés ou non, émanant des établissements d'enseignement et de recherche français ou étrangers, des laboratoires publics ou privés. 


\title{
Causality and conservation of energy: their implications for prediction of receiver performance
}

\author{
D.E. LEIKIN
}

Institute of Acoustics, Russian Academy of Sciences, 4 Shvernik Street, 117036 Moscow, Russia

\begin{abstract}
: the paper is concemed with the analysis of receiver performance in range-dependent waveguldes. The problem is shown to be amenable to a simple theoretical treatment. The necessary analytical technique is based on the application of the principle of causality and the law of conservation of energy. The focus of the analjsis is on prediction of limiting capabilities of an optimum detector of quasi-deterministic signals in irregular mult1-mode channels. Fxpliclt analytical formulae are derived for the probability of detection, the far-fleld directivity function and the Cramer-Rao bound for mean-root-square errors in estimates of signal parameters. The theory presented reveals clear physical limits on capabilities of slgmal processing technique in nonuniform oceanic environment.
\end{abstract}

\section{TNTRODUCTION}

Theoretical prediction of receiver performance in non-uniform channels is a tough problem. Conventional stralghtforward technique requires accurate transmission models to be specified. Such an approach makes 1t impossible to examine reception characterlstics under realistic conditions since the governing wave equation cannot be solved analgticalig in range-dependent medium.

In this paper, an alternative approach is proposed. It is demonstrated that application of the first principles allows one to bypass the necessity to solve the wave equation. This enables theoretical analysis to be carried out in ignorance of the actual transfer function of the transmission channel. The reviewed technique provides a vivid insight into the physical essence of the problem.

\section{WAVE FRONT REVERSAL}

Let us first consider the auxiliary problem of phase-confugation. Assume that the sound fleld of a point source in a multi-mode range-dependent channel is reversed by a remote vertical aperture. The complex-valued amplitude distribution of the phase-conjugated wave will be given by the integral 


$$
A_{s f} \equiv A\left(\vec{x}_{s}, \vec{x}_{f}\right)=\int G^{*}\left(\vec{x}_{,} \vec{x}_{f}\right) G\left(\vec{x}_{,} \vec{x}_{s}\right) d z,
$$

where $\vec{x}=(x, y, z), G(1,2)$ is the Green function of the governing wave equation, and the subscript $s$ ( $f$ ) indicates co-ordinates of the source (observation polnt). At low frequencles sound transmission in the underwater channel is known $[1,2]$ to be characterized by relatively small absorption and scattering losses. This fact enables the Green function $G(1,2)$ to be expressed in terms of the mode-conversion matrix $U(1,2)$ whose elements are given by complex-valued functionals depending on spatial variations of the refractive index of the channel within the glven range interval along the propagation route. The princlple of causality demands that the conversion matrix should satisfy the relation

$$
U(1,2)=U(1, P) U(P, 2),
$$

where $P$ in an arbitrary intermediate range. There is one more fact that can be learmed about $U(1,2)$ from the first principles. Namely, the conversion matrix has to be unitary in order to meet the law of energy conservation:

$$
\mathrm{U}^{+} \mathrm{U}=\mathrm{U} \mathrm{U}^{+}=I \text {. }
$$

The Information provided by Eqs.(2,3) is quite sufficient for one to calculate the amplitude distribution (1) near the focal point. In order to cast the final result into the most appropriate form it is convenient to introduce the form factor

$$
W_{s f}=A_{s f} /\left(A_{s s} A_{f f}\right)^{1 / 2} \text {. }
$$

In multi-mode channels. the form factor is found to be given by

$$
w_{s f}=[2 \sin (g)]^{-1} \int_{-g}^{+g} \exp [1 k \vec{q} \vec{n}(u)] \cos (u) d u,
$$

where $\vec{n}(u)=[\sin (u), \cos (u)]$ is a unit vector in the range-depth plane, $k$ Is the wavenumber.

$$
\vec{q}=(\Delta z, \Delta r) \equiv\left(z_{s}-z_{f}, r_{s}-r_{f}\right)
$$

denotes spatial separation between the focal polnt and the observation point, and the limiting angle

$$
B=\arcsin \left(J_{s}\right)
$$

corresponds to the near-source value of the channel's trapping factor $J$. (The latter is defined by the ratio of the energy trapped into the channel to the total irradiated energy [2,p.111].) Thus the near-focus amplitude distribution of the wave front reversal is shown to be Independent of the channel structure along the propagation route.

\section{SIGNAL DETECTION}

Suppose that a signal is to be detected in a broad-band Gaussian nolse of mean zero. Let the observed sound field $\nabla(z, \forall, z, t)$ be sampled by a vertical hydrophone array which is able to resolve the propagating modes trapped by the channel. In order to olarify the further analysis assume that: (1) the spectral density of the nolse varies inslgnificantly within the frequency range of the expected stgnal, (ii) the noise fluctuations do not correlate at different hydrophones. The expected signal is assumed to be produced by a point source emitting into the channel of some non-untform sound speed distribution $c(x, \nabla, z)$. The emitted slgnal $s(t)$ is specified, however, the remaining parameters of the source constitute an unknown vector $f$ 


$$
\underline{I}=\left(a_{s}, r_{s}, z_{s}\right) \text {, }
$$

where ' $a$ ' Is the amplitude of the emitted signal, $r$ is the range measured horlzontally from the receiver, and $z$ is the depth measured downward from the surface. The problem of signal detection/estimation can be treated through the use of the likelihood conoept [3]. Under the conditions assumed, the optimum receiver should calculate the coherent amplitude of the wave front reversal. If the observation time is sufficientiy large, the response of the Ilkelihood detector will be given by

$$
I[v(z, t) \mid \vec{f}]=\int s(\omega) \int G\left(\vec{x}, \vec{x}_{f}\right) v^{*}(\vec{x}, \omega) d z d \omega,
$$

where $s(\omega)$ and $\nabla(\omega)$ denote corresponding signals in frequency domain. Since statistic $I$ is a Gaussian random variable, the probability of detection for a flxed $\vec{f}$ will be given by the error function integral

$$
Q(\vec{f})=\operatorname{erfc}[D(\overrightarrow{\mid})-\Lambda] \text {. }
$$

where $D(\vec{f})$ denotes the output signal-to-nolse ratio (BNR), and $\Lambda$ is the pre-assigned decision level. Were the signal parameters known exactly. $D(f)$ would attain its limiting value

$$
D_{o p t}^{2}=A_{s s} E / N_{0}=J_{s} E / 8 \pi^{2} N_{0} r_{s} \text {. }
$$

where $F$ denotes total irradiated energy. It is convenient, therefore, to Introduce the loss factor

$$
F(\vec{f})=D(\vec{f}) / D_{\circ p t}
$$

that will indicate the SNR decrease due to mismatch in signal parameters. The loss factor can now be expressed in terms of the "correlation" function of the emitted signal

$$
B_{s}(\tau)=\int s(t) s(t-\tau) d t / \int s^{2}(t) d t .
$$

Using the result (4), one obtains ( $0_{s}$ is the near-source sound velocity)

$$
F(\Delta z, \Delta r)=[2 \sin (g)]^{-1} \int_{-g}^{+g} B_{s}\left[\vec{q} \vec{h}(u) / c_{s}\right] \cos (u) d u .
$$

This general relation determines the limiting far-field directivity function of the optimum detector in non-uniform waveguide channels.

The response of the matched processor (5) will have one principal peak near the true values of slonal parameters. The shape of this peak reproduces that of the loss factor,

$$
\langle I[v(z, t) \mid \vec{I}]\rangle \propto F(\Delta z, \Delta r) \text {. }
$$

Since the nolse is also present, the princlpal peak will be surrounded by multiple additional maxima caused by the nolse fluctuations. What form will these random peaks have? In order to answer this question one has to calculate the correlation function

$$
\Psi(1,2)=\langle I(1) I(2)\rangle-\langle I(1)\rangle\langle I(2)\rangle
$$

of the receiver response $I(\vec{I}) \equiv I[\nabla(z, t) \mid \vec{I}]$ in the space of the signaI parameters. It may seem a surprise, but this problem can also be solved for arbitrary channel, provided that assumption (11) holds. By using the first principles $(2,3)$ it may be verified that

$$
\Psi(1,2) \cong \Psi\left(\vec{f}_{1}-\vec{f}_{2}\right) \propto F(\Delta z, \Delta r) \text {. }
$$

Thus the spurious maxima of the nolse clutter will have the same shape as the principal signal peak. Note that the noise clutter is independent of the chamel structure along the propagation route. 


\section{ESTIMATION OF SIGNAL PARAMETERS}

The last problem to be discussed concerns the attalnable accuracy of the estimates of the signal parameters. Suppose that unbiased estimates $f$ of the unknown parameters were obtained. At large SNR the covarlance matrix

$$
\mathbf{B}=\left\langle\hat{\delta} \overrightarrow{\mathbf{f}} \delta \overrightarrow{\mathbf{I}}^{+}\right\rangle
$$

of errors $\delta \vec{I}=\vec{I}-\langle\vec{I}\rangle$ in these estimates can be determined through the Cramer-Rao inequality. The corresponding lower bound is given by the Inverse of the Information matrix whose elements can be calculated by differentiating the generalized ambiguity function. The latter is found to be related closely to the form factor of the channel:

$$
H(1,2)=a_{1} a_{2} J_{s}\left[4 \pi\left(r_{1} r_{2}\right)^{1 / 2} N_{0}\right]^{-1} \int|s(\omega)|^{2} w_{12} d \omega \text {. }
$$

Calculating the elements of the information matrix (terms of order $1 /$ [range squared] omitted), one obtains

$$
B=\left[c_{s} / D_{o p t} \Delta \omega\right]^{2}\left|\begin{array}{ccc}
{\left[a_{s} \Delta \omega / c_{s}\right]^{2}} & 0 & 0 \\
0 & 1 & 0 \\
0 & 0 & 3 / J_{s}^{2}
\end{array}\right| .
$$

where $D_{\text {opt }}$ is the Iimiting signal-to-nolse ratio defined by (6), $c_{s}$ is the sound velocity near the source, and $\Delta \omega$ is the mean-root-square deviation of the emitted spectrum

$$
\Delta \omega^{2}=\int|s(\omega)|^{2} \omega^{2} d \omega / \int|s(\omega)|^{2} d \omega .
$$

Note that the optimum amplitude-range-depth estimates w111 always be uncorrelated for arbitrary channel structure along the route.

\section{CONCLUSIONS}

It has been demonstrated that proper application of the first principles allows IImiting capabilities of the matched receiver to be analyzed in Ignorance of the transfer function of the channel. Reception characteristics, such as detection probabllity, the far-field directivity function and the Cramer-Rao bound for errors in amplitude-range-depth estimates, were shown to be determined completely by two physloal parameters of the transmisston channel, namely, by the near-source values of sound velocity and the trapping factor. The success of the reviewed approach lies in the fact that actual transfer function contains surplus information which is unnecessary for the analysis to be carried out since all important transmission characteristics were already allowed for in the course of wavegulde-detector matching.

\section{REFERENCES}

[1] Flatte S.M. et al. Sound transmission through a fluctuating ocean (Cambridge University Press, Cambridge, 1979).

[2] Brekhovskikh I.M. and Iysanov Yu.P. Fundamentals of the ocean acoustics (Springer-Verlag. Berlin Heldelberg, 1991).

[3] Helstrom C.W. Statistical theory of signal detection (Pergamon Press, Oxford, 1968) p.291. 